\title{
Language Proficiency in Preschool Children with Different Levels of Executive Function
}

\author{
Aleksander N. Veraksa*, Daria A. Bukhalenkova, Maria S. Kovyazina \\ Faculty of Psychology, Lomonosov Moscow State University, Moscow, Russia \\ *Corresponding author. E-mail: veraksa@yandex.ru
}

Background. According to numerous studies, people's development of executive function is a predictor of their successful acquisition of literacy skills. However, the data on the relationship between the development of verbal language and executive function in preschool aged children are insufficient and contradictory.

Objective. The goal of our research was to study the connection between the three main EF components (working memory, inhibition, and cognitive flexibility) and various spoken language skills in children of senior preschool age. It is the first stage of a longitudinal study aimed at understanding the relationship between executive function and language development starting from ages 5-6, and proceeding through elementary school.

Design. Our study sample included 279 children aged 5-6 years $(M=5.6$ years) attending a senior group in Moscow kindergartens (139 boys and 140 girls). The study used NEPSY-II diagnostic complex subtests and the Dimensional Change Card Sort (DCCS) test to measure the level of executive functions (working memory, cognitive flexibility, and inhibition). Language development (vocabulary, phonemic awareness, and word generation) was measured by neuropsychological methods (Akhutina, Pylaeva, 2015).

Results. The results of the study showed significant associations between all EF components and language skills development in preschool children. Oral language skills were more closely related to the level of development of verbal working memory and cognitive flexibility than they were to inhibition or visual working memory. Children with low levels of EF development were significantly less able to cope with tasks such as understanding prepositional structures, understanding similar sounding words, and showing verbal fluency, than children with a high EF level. Furthermore, children with normal and high levels of EF development displayed no significant differences in language development. Thus, the study showed that children with a low level of EF have difficulties with language development.

Conclusion. Our results provide important details about understanding the relationship between executive functioning and language development in children of senior preschool age.

Keywords: Preschool age, executive function (EF), language, vocabulary, phonemic awareness, word generation. 


\section{Introduction}

The levels of executive function (EF) and language development are major indicators of development in preschool children (Vygotsky, 1984), forming the basis for school readiness (Elkonin, 2006; Matthews, Ponitz, \& Morrison, 2009), and serving as predictors of further academic achievement (Blair \& Razza, 2007; Duff et al., 2015; Duncan et al., 2007; Willoughby et al., 2012).

According to numerous studies, EF development is a predictor of the successful acquisition of reading and writing skills (Aaron et al., 2008; Cutting et al., 2009; Cantin et al., 2016; Yeniad et al., 2013). However, the data on the relationship between verbal speech and EF in children of preschool age are insufficient and contradictory (Pazeto, 2014). There are ongoing efforts to do theoretical and empirical research in this area, as evidence is building up in favor of the view that the level of EF predicts language development (Blair et al., 2012, Henry, Messer, \& Nash, 2012; Verhagen \& Leseman, 2016). Conversely, there are longitudinal studies which have shown that expressive language in childhood predicts later development of EF (Kuhn et al., 2014; Petersen et al., 2013).

\section{Executive function}

One of the most significant models for understanding EF development has been proposed by Miyake and his colleagues (Miyake et al., 2000). According to this model, the neuropsychological basis for mastering one's behavior is formed by a group of cognitive skills that enable targeted problem-solving and adaptive behavior in new situations. According to this approach, EF is divided into the following three main components: 1) working memory; 2) cognitive flexibility, which is associated with the ability to switch from one rule to another; and 3) inhibitory control, which is supposed to inhibit one's dominant response to a situation in favor of what a task requires. Although originally based on the results obtained for adults, the applicability of this model to describe child development has been confirmed in a number of studies (Diamond \& Lee, 2011; Lehto et al., 2003, Visu-Petra et al., 2013; Almazova et al., 2016).

\section{Connection between EF and language skills}

The existence of a link between EF and language development in preschool age children has been shown in a number of correlation studies (Blair \& Razza, 2007; Matthews, Ponitz, \& Morrison, 2009). For example, Blair and Razza (2007) analyzed the relationship between two EF components (inhibition and switching), on the one hand, and various academic skills, including speech, on the other. The study involved 170 children aged 3-5 years. The development of inhibition proved to be significantly related to a child's vocabulary, phonological processing abilities, and letter knowledge, while switching turned out to be associated with vocabulary only. The researchers suggested that these outcomes may support the idea that inhibition is instrumental in the development of academic skills for children of preschool age (Blair \& Razza, 2007).

A study by Matthews and colleagues (2009), which was conducted on a sample of 268 3-5 year-old children, revealed a correlation between self-regulation (a multicomponent variable which depends on cognitive skills, including working mem- 
ory, attention control and switching, and inhibitory control) and sound awareness, whereas its link to vocabulary development (Picture Naming Test) was not established (Matthews, Ponitz, \& Morrison, 2009). Many studies have also shown a link between executive function, and reading and writing skills in the senior preschool and junior school years (Cutting et al., 2009; Diamond, 2006; Duncan et al., 2007)

The relationship between EF and language development in preschool-aged children has also been revealed by longitudinal studies. Fuhs and Day (2011) studied the dynamics of EF and language development in 132 children aged 4-5 years for one academic year. At the beginning and end of the school year, they diagnosed the development of two EF components (inhibition and switching) and assessed the children's school readiness. When processing the autumn and spring data separately, they found a significant connection between both EF components and the receptive vocabulary. However, none of the EF components were associated with the results of the tests measuring expressive vocabulary (as shown in the Picture Naming subtest of the WPPSI-III). The study also showed that children with a receptive vocabulary and a high level of phonological awareness (according to the WPPSI) are significantly more successful in developing inhibition and switching abilities than children with average and low levels of verbal ability (Fuhs \& Day, 2011).

In a study by Fuhs and colleagues (2014), 562 four-year-old children were assessed at the beginning and end of their prekindergarten year, and followed to the end of kindergarten. Researchers report that strong bidirectional associations were found for the generalized indicators of EF and oral comprehension skills, but not for literacy skills in the pre-K year. In addition, after controlling for pre-K gains in both EF and achievement, EF skills continued to be a moderate predictor of kindergarten language gains (Fuhs, Nesbitt, \& Farran, 2014).

Evidence of such association discovered later in a study by Pazeto and colleagues (2014) analyzed the dynamic relationship between EF and language development in children of preschool age. The study involved 90 children aged 4-5 years who were tested in their final year of kindergarten and in the first grade. The study revealed significant changes in the level of spoken language competence and reading and writing skills, while the level of development of all EF components, except for voluntary attention, remained more or less unchanged. This result shows that language skills develop faster than EF does in children of preschool age. Correlation analysis showed that the levels of EF and spoken language competence are significantly associated with the development of reading and writing skills, whereas EF and spoken language skills appear to be relatively more independent of each other.

Similar results showing the dynamic relationship between EF and language development were obtained in longitudinal studies by Bohlmann and colleagues (2015) and by Slot and Suchodoletz (2018). Bohlmann and colleagues revealed a link between the vocabulary and self-regulation skills in 250 children aged 3-5 years. The preschool children underwent three measurement waves during a period of two years. The results showed that there is a bidirectional relationship between the variables studied: the larger the child's vocabulary had been before the study began, the greater the results he or she achieved in the development of cognitive control during the study period; likewise, the level of executive control development determined the intensity of vocabulary growth. The study by Slot and Suchodoletz (2018) was aimed at assessing the dynamics of language and EF development in 
227 children aged 3-4 years. When they entered kindergarten, all the children had their actual level of language and EF development measured, and these levels were later compared with the end-of-school year data. A bidirectional association was found to exist between the development of language and of EF. The authors concluded that language development is important for stimulating the development of EF (Slot \& Suchodoletz, 2018).

A number of studies have shown a connection between EF and children's vocabulary (Blair \& Razza, 2007; Fuhs \& Day, 2011; Bohlmann, Maier, \& Palacios, 2015). However, some of the results are contradictory (Matthews, Ponitz, \& Morrison, 2009). It is interesting to note that the picture-naming task often tends to be unrelated to EF components (Matthews, Ponitz, \& Morrison, 2009; Fuhs \& Day, 2011). Other studies found a statistically significant connection between listening comprehension and EF at the preschool age (Blair \& Razza, 2007; Matthews, Ponitz, \& Morrison, 2009; Fuhs, Nesbitt, \& Farran, 2014), unlike a large number of studies showing the relationship between EF and reading and writing skills (Cutting et al., 2009; Diamond, 2006; Duncan et al., 2007). However, the mechanism of this association has not been studied sufficiently (Pazeto et al., 2014). It is also noteworthy that many studies (e.g., Blair \& Razza, 2007; Fuhs \& Day, 2011) consider only two EF components-inhibition and switching-whereas the connection between working memory and language skills has been studied to a lesser extent.

Consequently, most of the longitudinal studies have established a bidirectional relationship between EF and language development in preschool children (Zelazo et al., 2003; Fuhs \& Day, 2011; Slot \& Suchodoletz, 2018). These data are also supported by the research of Henry and colleagues (2012), which showed that children with language impairments had much lower EF developmental outcomes (verbal and nonverbal working memory, inhibition and planning) than those with normative language development parameters. Researchers note that difficulties remained even after the diagnostic tasks were adapted to match the children's speech abilities (Henry, Messer, \& Nash, 2012).

Another group of studies found a significant predictive relationship between children's EF measured in the fall of preschool, and their receptive vocabulary measured in the following spring (Blair \& Razza, 2007; Montgomery, Magimairaj, \& Finney, 2010; Rose, Feldman, \& Jankowski, 2009; Verhagen \& Leseman, 2016; Weiland et al. 2014). For example, the study by Rojas-Barahona and colleagues (2015) found statistically significant changes in the rate of language development taking place after children were given classes designed to develop their working memory.

The third point of view is based on the model that sees language and EF development as mutually stimulating processes (Bohlmann, Maier, \& Palacios, 2015), a view which is consistent with the cultural-historical approach to understanding language development and self-regulation in child development (Vygotsky, 1962; Luria, 1976; Reshetova, 2017).

The data presented in this paper are based on the first wave of a longitudinal study aimed at understanding the EF-language relationship in children starting from ages 5-6, and continuing through elementary school. The goal of this research was to study the connection between all three main EF components (working memory, inhibition, and cognitive flexibility) and various spoken language skills in senior preschool age. 


\section{Methods}

\section{The sample and procedure of the study}

Our sample included 279 children aged 5-6 years ( $M=5.6$ years) who were attending a senior group in Moscow kindergartens (139 boys and 140 girls). All tasks were carried out by the children in the spring of 2017, individually, in a quiet room. The parents of the preschool children gave their written informed consent for their children's participation in the study. The procedure was approved by the Board of Ethics, Faculty of Psychology, Lomonosov Moscow State University.

\section{Measures of EF}

The test battery consisted of tasks that explored three main EF components in children: working memory, cognitive flexibility, and inhibitory control. Most of methods used in the study were Russian versions of subtests from the neuropsychological complex NEPSY-II, which is designed to evaluate children's mental development within the age bracket of 3-16 years (Korkman, et al., 2007). Previous research has shown the possibility of using these tests on Russian preschool children (Almazova, Bukhalenkova, \& Veraksa, 2016).

To assess verbal working memory, a subtest of the NEPSY-II Sentence Repetition $(S R)$ was used. This subtest is designed to assess the ability to repeat sentences of increasing complexity and length. A series of sentences was read to a child, who was then asked to reproduce each sentence immediately upon its presentation. Each correct repetition of the sentence scores two points. If the child makes one or two mistakes, the sentence is scored one point; if more mistakes are made, the sentence is scored 0 points.

To estimate visual working memory, a subtest of the NEPSY-II Memory for Designs $(M D)$ was used. It is designed to assess spatial memory for novel visual material. The child is shown a grid with four to eight designs on a page, which is then removed from his or her view (subtests 2-5). The child selects the designs from a set of cards, and places the cards on the grid in the same location as was shown previously. Points are scored separately for correctly remembering the spatial $(\max =48)$ and content $(\max =24)$ characteristics of the images. Bonus points are scored for correctly remembering the integral configurations of the objects and image details $(\max =48)$.

To assess the level of cognitive flexibility, the Dimensional Change Card Sort (DCCS) method was used (Zelazo, 2006). The children are required to sort a series of bivalent test cards, first according to one dimension (color), and then according to another (shape). On the third sorting, a child had to sort the cards according to an additional factor (cards with borders/cards without borders). The test measures the child's ability to regulate his/her behavior according to complex rules, thereby assessing the level of the child's cognitive flexibility.

To assess the level of inhibition development, the Inhibition subtest of the NEPSY-II was used. It is designed to assess the ability to inhibit automatic responses in favor of novel responses, and the ability to switch between types of responses. During the first step, the child looks at a series of shapes (squares and circles) and names the shape as quickly as possible (Naming).Then, having named the shapes, he/she has to switch to an alternate response ("circle" instead of "square" and vice 
versa) (Inhibition). The researcher calculates the number of the children's corrected and uncorrected mistakes, and the time it takes them to complete each phase.

\section{Measures of language development}

We measured the preschoolers' vocabulary (naming objects and actions, understanding of logical and grammatical constructions), phonemic awareness (understanding similar sounding words), and word generation (the ability to actualize words).

The Picture Naming subtest of the WPPSI (2006) (Rzhanova et al., 2018) is aimed at measuring the preschoolers' vocabulary. This technique consists of 18 pictures depicting various images that are shown to the child one by one, which he/ she should identify. The child is awarded one point for each correctly performed task. At the end, the total score is calculated for each task (the maximum amount being 18 points).

The Naming of Actions (Akhutina, 2016) aims at measuring the preschoolers' vocabulary (the nominative function of speech). It consists of 15 pictures depicting different actions. The child is shown pages with images and asked to name what it is depicted there with one word. The child is awarded three points for giving the exact name; two points for answering by using several words; one point for similar verbal substitutions or distortion of the sound structure of the word; and zero points for an incorrect answer or a noun substitution for a verb. Then the total score is calculated for all the tasks (45 points at most).

The method of Understanding of Logical Grammatical Constructions (ULGC) (Akhutina, 2016) begins with examining the children's understanding of active and passive constructions with direct and reverse word order. The child is offered a sheet with pairs of pictures depicting variants of reversible situations (for example, "a girl is caught by a boy"). The researcher reads the sentence and asks the child to show the picture that matches it. Overall, seven sentences are presented, and one point is awarded for every correctly performed task. The second part examines the understanding of prepositional constructions. The material consists of a set of pictures depicting different mutual spatial arrangements of a box and a keg. The child is asked to show which picture the arrangement of the objects matches (for example, "there's a keg behind the box"). Overall, six prepositional constructions are presented.

The method of Understanding of Similar Sounding Words (USSW) (Akhutina, 2016) was used to measure a child's phonemic awareness and verbal working memory. The child is given two sheets that have ten pictures depicting objects with similar sounding names. At first, the child is asked to name all the objects. Then the child is given the names of several objects, which he or she is to memorize and show in the same order in which they were presented. The number of items named gradually increases from two to six. Children aged 4-5 years are given tests that grow in complexity until they make mistakes in three tasks in a row. In each assignment, the child is awarded one point for every correctly identified picture (productivity). Additional points are also awarded for duplications (if the child gives the right word and a similar sounding one, he gets one point), for changed word order (one point), omissions (one point), and superfluous words (one point). 
The Verbal Fluency Test (VFT) (Akhutina, 2016) is aimed at measuring the word actualization process and verbal fluency. It consists of three tasks: the first one is based on free associations (a child is asked to give as many words as possible within a minute). Tasks two and three involve directed associations: in two, the child is asked to name a series of actions for a minute, and in three, to name a series of animals (While the original test, aimed at elementary school age children, called for naming a series of plants, we replaced plants with animals, as more appropriate for preschool children). A similar task is found in NEPSY-II (Korkman et al., 2007). In each task, we calculated the number of productive associations, i.e., all words without repetition and inadequate words.

\section{Results}

\section{Descriptive statistics}

Since the validation of language assessment was carried out on first-graders, let us first consider the results of these tests for 5-6 years old children (See Table 1).

Table 1

Descriptive statistics of language skills measurements in senior preschool age

\begin{tabular}{lcc}
\hline & Mean & Standard deviation \\
\hline Picture Naming & 13.09 & 1.970 \\
Naming of Actions & 8.73 & 3.073 \\
ULGC, active, passive constructions & 4.57 & 1.430 \\
ULGC, prepositions & 2.68 & 1.420 \\
USSW, productivity & 17.45 & 7.295 \\
VFT, free associations & 17.06 & 7.344 \\
VFT, actions & 7.91 & 3.517 \\
VFT, animals & 11.89 & 4.525 \\
\hline
\end{tabular}

We observe big standard deviation in the Understanding of Similar Sounding Words test (USSW) implementation that indicates the differences in the development of the phonemic awareness or verbal working memory of the preschoolers. The results of the Picture Naming test and the Understanding of Logical Grammatical Constructions method (ULGC) indicate about the same level of development of children's vocabulary. At the same time, the children vary in performing word generation tasks: naming animals turns out to be easier than naming actions.

\section{Analysis of the correlation between the indicators of EF and language skills development}

Since one of the tasks at this stage was to examine which EF components were associated with different language skills, we turned to the correlation analysis of the data (See Table 2). 
Table 2

Results of the correlation analysis of EF and language skills measurements (Spearman's coefficient and significance level)

\begin{tabular}{|c|c|c|c|c|c|c|c|c|c|c|c|}
\hline & \multicolumn{4}{|c|}{ Visual WM } & \multirow{2}{*}{ 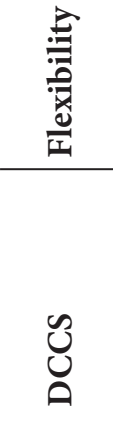 } & \multirow{2}{*}{ 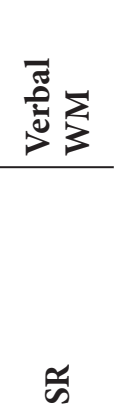 } & \multicolumn{5}{|c|}{ Inhibition } \\
\hline & 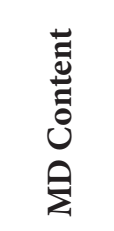 & 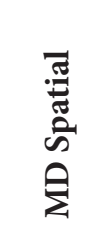 & 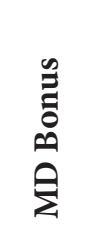 & 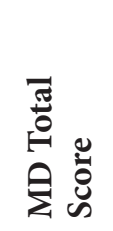 & & & 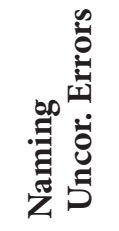 & 艺 & 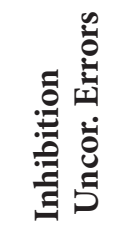 & 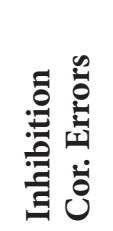 & 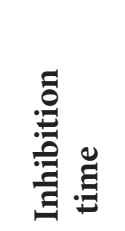 \\
\hline \multirow{2}{*}{ 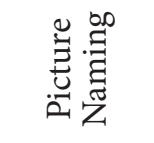 } & .110 & .012 & .029 & .054 & $.147^{\star}$ & $.363^{\star *}$ & -.066 & -.090 & $-.125^{\star}$ & -.084 & \\
\hline & .072 & .847 & .633 & .380 & .014 & .000 & .281 & .143 & .042 & .171 & \\
\hline \multirow{2}{*}{ 胥芯葛 } & -.076 & .019 & .027 & -.004 & .098 & .075 & .003 & -.078 & $-.142^{\star}$ & .114 & \\
\hline & .211 & .751 & .662 & .942 & .102 & .209 & .961 & .203 & .021 & .062 & \\
\hline \multirow{2}{*}{ 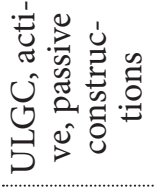 } & $.139^{\star}$ & .074 & .093 & .113 & $.252^{\star *}$ & $.317^{\star *}$ & $-.165^{\star *}$ & $-.180^{\star *}$ & $-.139^{\star}$ & .068 & $-.180^{\star *}$ \\
\hline & .023 & .224 & .128 & .064 & .000 & .000 & .007 & .003 & .023 & .271 & .003 \\
\hline \multirow{2}{*}{ 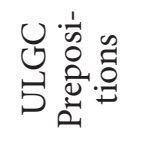 } & $.132^{\star}$ & $.140^{\star}$ & $.126^{*}$ & $.148^{\star}$ & $.270^{\star *}$ & $.354^{\star *}$ & -.077 & -.052 & $-.162^{\star \star}$ & $-.124^{\star}$ & $.132^{\star}$ \\
\hline & .031 & .022 & .038 & .015 & .000 & .000 & .209 & .398 & .008 & .043 & .031 \\
\hline \multirow{2}{*}{ 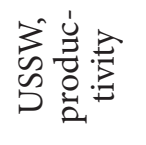 } & $.177^{\star *}$ & $.166^{\star *}$ & $.157^{\star}$ & $.185^{\star *}$ & $.321^{\star *}$ & $.526^{\star *}$ & $-.190^{\star *}$ & -.110 & $-.210^{\star *}$ & .001 & -.094 \\
\hline & .004 & .006 & .010 & .002 & .000 & .000 & .002 & .072 & .001 & .989 & .128 \\
\hline \multirow{2}{*}{ 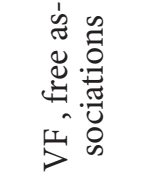 } & .074 & $.128^{\star}$ & $.142^{\star}$ & $.129^{\star}$ & $.133^{\star}$ & $.237^{\star \star}$ & -.084 & $-.219^{\star *}$ & .032 & .097 & -.106 \\
\hline & .248 & .047 & .028 & .046 & .035 & .000 & .197 & .001 & .624 & .135 & .103 \\
\hline \multirow{2}{*}{ 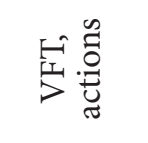 } & .123 & .093 & .110 & .114 & .049 & $.279^{\star *}$ & -.063 & $-.135^{\star}$ & -.054 & $.160^{\star}$ & $-.132^{\star}$ \\
\hline & .052 & .142 & .083 & .072 & .436 & .000 & .324 & .034 & .398 & .012 & .038 \\
\hline \multirow{2}{*}{ 坫菉 } & .078 & .067 & .072 & .082 & $.167^{\star *}$ & $.314^{\star *}$ & -.041 & $-.160^{\star *}$ & -.009 & -.052 & $-148^{\star}$ \\
\hline & .211 & .283 & .249 & .190 & .006 & .000 & .510 & .010 & .881 & .406 & .018 \\
\hline
\end{tabular}

Note. ${ }^{* *}$ correlation is significant at the level of $0.01,{ }^{*}$ correlation is significant at the level of 0.05 
The results of both naming tasks (Picture Naming and Naming of Actions) are significantly associated with the level of development of verbal working memory (SR), and they are inversely correlated with the number of mistakes in the Inhibition method (the fewer mistakes children make, the better they cope with the naming task), which indicates the link with the ability to self-correct. It is interesting to note that only the Picture Naming subtest has a significant correlation with cognitive flexibility (DCCS).

A large number of significant correlations were found between the understanding of logical grammatical constructions (ULGC) and tasks on cognitive flexibility (DCCS), verbal working memory (SR), and inhibition. It is noteworthy that the understanding of active and passive constructions correlates only with the aspect of image detail memorization (MD Content) rather than the overall score. At the same time, the task of understanding prepositions significantly correlates with all indicators for visual working memory (content, spatial, and bonus scores).

The children's productivity in the Understanding of Similar Sounding Words task (USSW) was significantly associated with good results in the working memory tasks (both visual and verbal), cognitive flexibility, and the number of uncorrected errors in the Inhibition subtest, which reflects the information-processing speed. Such indicators as substitutions and omissions did not have significant correlations with the EF tasks. However, the mistakes associated with the naming of superfluous words in this task were significantly correlated with cognitive flexibility ( $\mathrm{r}=0.134, \mathrm{p}=0.025)$, and those of duplications were linked to the time of inhibition task performance $(r=0.165, p=0.007)$. In other words, the longer it takes a child to perform the task, the more duplication he has in the phonemic hearing test.

A child's productivity on all three tasks of the Verbal Fluency Test (VFT) (free, action, and animal associations) proved to be significantly associated with verbal working memory and with the time required for the Naming task in the Inhibition method, which reflects the speed of information processing. At the same time, the productivity of free association, unlike the others (animal and action word generation), also correlated with visual working memory. The productivity of free and animal word generation was also significantly associated with cognitive flexibility (DCCS), while action naming was not. However, the productivity of action word generation proved to be significantly inversely associated with the number of corrected mistakes, and was inversely related to the time it took to do the Inhibition task. This result indicates a connection between the ability to generate action words, and the level of inhibition development.

In sum, oral language skills have the greatest number of significant correlations with verbal working memory and cognitive flexibility.

\section{Language performance by children with different EF levels}

The cluster analysis (using the K-means method) of the results of the children's performance on the tests diagnosing cognitive regulation singled out three groups of children who differed on their level of EF development (Table 3). All differences between the clusters are significant, except for the number of corrected mistakes in the Inhibition task (Kraskell-Wallis criterion, $\mathrm{p} \leq 0,05$ ). 
It is important to note that children with high levels of EF development significantly differ from those with low levels of EF development on all indicators, except for the number of corrected mistakes in the Naming task of the Inhibition subtest (Mann-Whitney's criterion, $\mathrm{p} \leq 0.005$ ). In addition, children with low EF levels significantly differ in almost all parameters from those with medium EF level (Mann-Whitney's criterion, $\mathrm{p} \leq 0.005$ ). Only on the correct memorization of image details (MD Content) and the number of mistakes in both tasks on the Inhibition subtest are there no differences.

Table 3

Children with different levels of EF development (centers of clusters, cluster analysis using the K-means method)

\begin{tabular}{lccc}
\hline & $\begin{array}{c}\text { Low level } \\
\text { of EF }\end{array}$ & $\begin{array}{c}\text { Medium level } \\
\text { of EF }\end{array}$ & $\begin{array}{c}\text { High level } \\
\text { of EF }\end{array}$ \\
\hline Visual Working Memory (MD), Content & 34.96 & 35.60 & 43.79 \\
Visual Working Memory (MD), Spatial & 15.87 & 18.08 & 22.73 \\
Visual Working Memory (MD), Bonus & 10.76 & 12.68 & 34.08 \\
Visual Working Memory (MD), Total Score & 61.60 & 66.36 & 100.60 \\
Verbal Working Memory (Sentence Repetition) & 16 & 19 & 20 \\
Cognitive Flexibility (DCCS) & 17 & 19 & 19 \\
Naming, uncorrected errors & 0.9 & 0.8 & 0.5 \\
Naming, corrected errors & 1.2 & 0.9 & 1.3 \\
Naming, time & 61.82 & 43.15 & 43.25 \\
Inhibition, uncorrected errors & 5.2 & 4.2 & 2.1 \\
Inhibition, corrected errors & 2.4 & 1.9 & 2.6 \\
Inhibition, time & 85.09 & 55.59 & 56.70 \\
Number of children & 55 & 130 & 73 \\
\hline
\end{tabular}

Children with high and medium EF levels differ less significantly from each other: nor do they differ in the successful performance of the task on cognitive flexibility (DCCS) and verbal working memory (SR), or the time it takes to complete the Inhibition tasks (Naming and Inhibition time). However, at the same time, children with medium EF levels make more mistakes than those with high EF levels. Thus, children with a low level of executive function significantly differ from the other two groups in terms of the development level of all the EF components. Therefore, we compared only the two extreme groups-those with low and high level of EF-on the successful performance of language tasks.

Children with a high level of EF development were more successful in tasks involving understanding of prepositions, understanding of similar sounding words, and verbal fluency (Table 3). It is important to note that comparison of children with high and average EF levels did not produce significant differences. Thus, the results of the cluster analysis showed that it is precisely the low level of EF development which correlates with a low level of language development. 
Table 4

Differences in the performance of language tasks in children with high and low EF levels (the Mann-Whitney test)

\begin{tabular}{lccc}
\hline & $\begin{array}{c}\text { High level } \\
\text { of EF }\end{array}$ & $\begin{array}{c}\text { Low level } \\
\text { of EF }\end{array}$ & $\begin{array}{c}\text { Level of } \\
\text { significance }\end{array}$ \\
\hline ULGC, understanding of prepositions & 2.9 & 2.2 & 0.010 \\
USSW, productivity & 18.9 & 15.5 & 0.005 \\
VFT, free associations & 18.5 & 15.8 & 0.039 \\
VFT, actions & 8.6 & 7.4 & 0.048 \\
VFT, animals & 12.2 & 10.6 & 0.039 \\
\hline
\end{tabular}

\section{Discussion}

The purpose of this stage of the study was to analyze the interrelationship between EF components and indicators of language development in senior preschool children.

The results of the correlation analysis showed that the level of language development is significantly associated with the scores on the verbal working memory test. This relationship is logical and natural since the performance of a working memory task requires the involvement of language functions. Most tasks aimed at language measurement require one to keep words in one's memory, which makes language methods sensitive to the ability to process and retain auditory information in working memory. Thus, the Sentence Repetition subtest may be a good indicator of not only verbal working memory development, but of language development as well. Another explanation of this connection is provided by a theory that the development of EF, and in particular that of working memory, allows children to gradually identify and memorize individual words from the flow of speech interaction, which in turn helps them to increase their vocabulary (Blair et al., 2012; Montgomery, Magimairaj, \& Finney, 2010; Rose, Feldman, \& Jankowski, 2009; Verhagen \& Leseman, 2016; Weiland et al., 2014).

Tasks aimed at measuring the understanding of logical and grammatical constructions, and those on phonological processing abilities, have also proved to be associated with visual working memory. Among other reasons, this can be explained by the specifics of this task: the analysis of the large number of pictures the child has to choose from requires a certain level of development of visual working memory and, in particular, the analysis of the image details.

Most of the language indicators are significantly correlated with cognitive flexibility, which shows the need to switch from one word, picture, or task to others in the course of their performance. However, the results on the action-naming tasks (based on naming of pictures and verbal fluency test) were unrelated to this EF component. Furthermore, the task of action associations (VFT) was related to the level of development of the inhibitory process, in contrast to other tasks on verbal generation. We can assume that naming actions is more difficult than object naming for 5-6 year old children, and involves some other higher mental functions. 
The level of development of inhibitory processes has been significantly associated with the successful performance of the task of understanding logical and grammatical constructions (both on understanding active and passive constructions, and understanding prepositions). Perhaps children need to suppress wrong answers in the course of this task. This might also explain the appearance of redundant words and duplications when children perform the tasks on phonemic hearing: when choosing the right pictures, it is difficult for children to inhibit those words on which they reflected during the task, or have met in previous tests. Another explanation for this relationship may that of Zelazo and his colleagues (Zelazo et al., 2003), who believe that children need words in order to imagine carrying out a task before creating the hierarchical structure of the rules needed to solve the problem. It is quite possible that the level of vocabulary, and the ability to compose phrases, affect the emergence of EF. For example, when a child is learning to distinguish between the words "cat" and "frog," while being aware that both names are classified as "animals", he/she has to learn to organize concepts in a hierarchical order (Hall \& Waxman, 1993). This understanding of the rules resulting from the use of language may influence the development of the ability to organize the information necessary for cognitive processes, which includes such EF components as cognitive flexibility and inhibition (Zelazo et al., 2003).

Thus, oral language skills are more closely related to the level of development of verbal working memory and cognitive flexibility then to inhibition, which somewhat contradicts the assumption of Blair and Razza (2007) that inhibition is the most significant executive function for language development at preschool age.

The results of cluster analysis showed that children with low levels of EF development are significantly less able to cope with the tasks of understanding prepositional structures, understanding similar sounding words, and verbal fluency, compared to children with high EF levels; whereas children with normal and high levels of EF development display no significant differences in language development. Thus, a low level of EF development has a lot to do with language difficulties.

\section{Conclusion}

The results of our study revealed significant associations between all EF components and language skills development in preschool children. These results are consistent with most research in this area (Fuhs \& Day, 2011; Pazeto et al., 2014; Fuhs, Nesbitt, \& Farran, 2014, Bohlmann, Maier, \& Palacios, 2015; Slot \& Suchodoletz, 2018), and shows the need to further investigate the mechanisms behind this connection. Furthermore, we found that children with a low level of EF also have a low level of language development.

\section{Limitations}

The children's expressive skills were not fully analyzed in our study. For example, a correlation analysis of EF with the ability to construct long phrases and sequences was not included. Furthermore, we did not measure the children's articulation skills. Letter-reading abilities were not included in the study at this stage because they are not a part of the curriculum for 5-6 year old children in Russian kindergarten. 


\section{Acknowledgements}

This work was supported by a grant from the Russian Foundation For Basic Research No. 17-29-09112.

\section{References}

Aaron, P.G., Joshi, R.M., Gooden, R., \& Bentum, K.E. (2008). Diagnosis and treatment of reading disabilities based on the component model of reading. Journal of Learning Disabilities, 41(1), 67-84. https://doi.org/10.1177/0022219407310838

Akhutina, T.V. (2016). Methods of neuropsychological examination of children 6-9 years. Moscow: V. Sekachev.

Akhutina, T.V. \& Pylaeva, N.M. (2015). Overcoming learning disabilities: a vygotskian-lurian neuropsychological approach (2nd ed.). Moscow: Academia.

Almazova, O.V., Bukhalenkova D.A., \& Veraksa, A.N. (2016). Proizvol'nost' v doshkol'nom vozraste: sravnitel'nyi analiz razlichnykh podkhodov i diagnosticheskogo instrumentariia [The voluntariness in the preschool age: a comparative analysis of various approaches and diagnostic tools]. Natsional'nyi psikhologicheskii zhurnal [National Psychological Journal], 4(24), 14-22. https://doi.org/10.11621/npj.2016.0402

Blair, C. \& Razza, R.P. (2007). Relating effortful control, executive function, and false belief understanding to emerging math and literacy ability in kindergarten. Child Development, 78(2), 647-663. https://doi.org/10.1111/j.1467-8624.2007.01019.x

Blair, C., Protzko, J., \& Ursache, A. (2012). Self-regulation and early literacy. In S.B. Neuman, \& D.K. Dickinson (Eds.), Handbook of early literacy research (pp. 20-35). New York: Guilford.

Bohlmann, N.L., Maier, M.F., \& Palacios, N. (2015). Bidirectionality in self-regulation and expressive vocabulary: Comparisons between monolingual and dual language learners in preschool. Child Development, 86, 1094-1111. https://doi.org/10.1111/cdev.12375

Cantin, R.H., Gnaedinger, E.K., Gallaway, K.C., Hesson-McInnis, M.S., \& Hund, A.M. (2016). Executive functioning predicts reading, mathematics, and theory of mind during the elementary years. Journal of Experimental Child Psychology, 146, 66-78. https://doi. org/10.1016/j.jecp.2016.01.014

Rojas-Barahona, C.A., Förster, C.E., Moreno-Ríos, S., \& McClelland, M.M. (2015) Improvement of working memory in preschoolers and its impact on early literacy skills: A study in deprived communities of rural and urban areas. Early Education and Development, 26, 5-6, 871-892. https://doi.org/10.1080/10409289.2015.1036346

Cutting, L.E., Materek, A., Cole, C.A.S., Levine, T.M., \& Mahone, E.M. (2009). Effects of fluency, oral language, and executive function on reading comprehension performance. Annals of Dyslexia, 59(1), 34-54. https://doi.org/10.1007/s11881-009-0022-0

Diamond, A. (2006). The early development of executive functions. In E. Bialystok \& F.I.M. Craik (Eds.), Lifespan cognition: Mechanisms of change (pp. 70-95). New York, NY: Oxford University. https://doi.org/10.1093/acprof:oso/9780195169539.003.0006

Diamond, A. \& Lee, K. (2011). Interventions shown to aid executive function development in children 4 to 12 years old. Science, 333, 959-964. https://doi.org/10.1126/science.1204529

Duff, F.J., Reen, G., Plunkett, K., \& Nation, K. (2015). Do infant vocabulary skills predict schoolage language and literacy outcomes? Journal of Child Psychology and Psychiatry, 56(8), 848856. https://doi.org/10.1111/jcpp.12378

Duncan, G.J., Dowsett, C.J., Claessens, A., Magnuson, K., Huston, A.C., Klebanov, P., \& Japel, C. (2007). School readiness and later achievement. Developmental Psychology, 43(6), 14281446. https://doi.org/10.1037/0012-1649.43.6.1428 
Elkonin, D.B. (2006). Child psychology: studies textbook for students of higher educational institutions. Moscow: Academy.

Fuhs, M.W. \& Day, J.D. (2011). Verbal ability and executive functioning development of preschoolers at Head Start. Developmental Psychology, 47, 404-416. https://doi.org/10.1037/ a0021065

Fuhs, M.W., Nesbitt, K.T., Farran, D.C., \& Dong, N. (2014). Longitudinal associations between executive functioning and academic skills across content areas. Developmental Psychology, 50, 1698-1709. https://doi.org/10.1037/a0036633

Hall, D.G. \& Waxman, S.R. (1993). Assumptions about word meaning: Individuation and basiclevel kinds. Child Development 64, 155-1570. https://doi.org/10.2307/1131552

Henry, L.A., Messer, D.J., \& Nash, G. (2012). Executive functioning in children with specific language impairment. Journal of Child Psychology and Psychiatry, 53, 37-45. https://doi. org/10.1111/j.1469-7610.2011.02430.x

Korkman, M., Kirk, U., \& Kemp, S.L. (2007). NEPSY II. Administrative manual. San Antonio, TX: Psychological Corporation.

Kuhn, L.J., Willoughby, M.T., Wilbourn, M.P., Vernon-Feagans, L., Blair, C.B., \& The Family Life Project Key Investigators (2014). Early communicative gestures prospectively predict language development and executive function in early childhood. Child Development, 85, 1898-1914. https://doi.org/10.1111/cdev.12249

Lehto, J., Juujarvi, P., Kooistra, L., \& Pulkkinen, L. (2003). Dimensions of executive functioning: evidence from children. The British Journal of Developmental Psychology, 21, 59-80. https:// doi.org/10.1348/026151003321164627

Luria, A.R. (1976). Cognitive Development: Its Cultural and Social Foundations. Harvard University Press.

Matthews, J.M., Ponitz, C.C., \& Morrison, F.J. (2009). Early gender differences in self-regulation and academic achievement. Journal of Educational Psychology, 101(3), 689-704. https://doi. org/10.1037/a0014240

Miyake, A., Friedman, N.P., Emerson, M.J., Witzki, A.H., Howerter, A., \& Wager, T. (2000). The unity and diversity of executive functions and their contributions to complex "frontal lobe" tasks: A latent variable analysis. Cognitive Psychology, 41(1), 49-100. https://doi. org/10.1006/cogp.1999.0734

Montgomery, J.W., Magimairaj, B.M., \& Finney, N.C. (2010). Working memory and specific language impairment: An update on the relation and perspectives on assessment and treatment. American Journal of Speech-Language Pathology, 19(1), 78-94. https://doi. org/10.1044/1058-0360(2009/09-0028)

Pazeto, T.C.B., Seabra, A.G., \& Dias, N.M. (2014). Executive functions, oral language and writing in preschool children: Development and correlations. Paidéia (Ribeirão Preto), 24(58), 213-221. https://doi.org/10.1590/1982-43272458201409

Petersen, I.T., Bates, J.E., D’Onofrio, B.M., Coyne, C.A., Lansford, J.E., Dogde, K.A., ... \& Van Hulle, C.A. (2013). Language ability predicts the development of behavior problems in children. Journal of Abnormal Psychology, 122(2), 542-557. https://doi.org/10.1037/a0031963

Rojas-Barahona, C.A., Förster, C.E., Moreno-Ríos, S., \& McClelland, M.M. (2015). Improvement of working memory in preschoolers and its impact on early literacy skills: A study in deprived communities of rural and urban areas. Early Education and Development, 26(5-6), 871-892. https://doi.org/10.1080/10409289.2015.1036346

Rose, S.A., Feldman, J.F., \& Jankowski, J.J. (2009). A cognitive approach to the development of early language. Child Development, 80(1), 134-150. https://doi.org/10.1111/j.14678624.2008.01250.x 
Reshetova, Z.A. (2017). Psikhika i deiatel'nost'. Psikhicheskii mekhanizm usvoeniia [Mind and activity. Psychic mechanism of learning]. Natsional'nyi psikhologicheskii zhurnal [National Psychological Journal], 3(27), 40-55. https://doi.org/10.11621/npj.2017.0306

Rzhanova, I.E., Alekseeva, O.S., Fominykh, A.Ya., \& Parshikova, O.V. (2018). Indeks rabochei pamiati kak odin iz osnovnykh pokazatelei testa Vekslera dlia doshkol'nikov [The working memory index as one of the main scales of the Wechsler preschool and primary scale of intelligence - fourth edition]. Psikhologicheskie Issledovaniya [Psychological research], 11(57), 8. Retrieved from http://psystudy.ru/index.php/num/2018v11n57/1529-rzhanova57.html

Slot, P.L. \& Suchodoletz A. (2018). Bidirectionality in preschool children's executive functions and language skills: Is one developing skill the better predictor of the other? Early Childhood Research Quarterly, 42, 205-214. https://doi.org/10.1016/j.ecresq.2017.10.005

Verhagen, J. \& Leseman, P. (2016). How do verbal short-term memory and working memory relate to the acquisition of vocabulary and grammar? A comparison between first and second language learners. Journal of Experimental Child Psychology, 141, 65-82. http://dx.doi. org/10.1016/j.jecp.2015.06.015

Visu-Petra, L., Cheie, L., Benga, O., \& Miclea, M. (2012). The structure of executive functions in preschoolers: An investigation using the NEPSY battery. Procedia - Social and Behavioral Sciences, 33, 627-631. https://doi.org/10.1016/j.sbspro.2012.01.197

Vygotsky, L.S. (1962). Thought and language. Oxford, England: Wiley. https://doi. org/10.1037/11193-000

Vygotsky, L.S. (1984). Child psychology. Vol. 4. In Collected works in 6 volumes. Moscow: Pedagogy.

Weiland, C., Barata, M.C., \& Yoshikawa, H. (2014). The co-occurring development of executive function skills and receptive vocabulary in preschool-aged children: A look at the direction of the developmental pathways. Infant and Child Development, 23, 4-21.

Willoughby, M.T., Kupersmidt, J.B, \& Voegler-Lee, M.E. (2012). Is preschool executive function causally related to academic achievement? Child Neuropsychology: A Journal on Normal and Abnormal Development in Childhood and Adolescence, 18(1), 79-91.

Yeniad, N., Malda, M., Mesman, J., van IJzendoorn, M. H., \& Pieper, S. (2013). Shifting ability predicts math and reading performance in children: A meta-analytical study. Learning and Individual Differences, 23, 1-9. https://doi.org/10.1016/j.lindif.2012.10.004

Zelazo, P.D. (2006). The Dimensional Change Card Sort (DCCS): a method of assessing executive function in children. National Protocols, 1, 297-301. https://doi.org/10.1038/nprot.2006.46

Zelazo, P.D., Muller, U., Frye, D., \& Marcovitch, S. (2003). The development of executive function in early childhood. Monograph of the Society for Research in Child Development, 68(3). https://doi.org/10.1111/j.0037-976X.2003.00261.x 